\title{
Analyticity, Truthmaking and Mathematics
}

\author{
Adrian Heathcote \\ Telegraph Rd. Pymble, NSW, Australia \\ Email: adrian.heathcote@bigpond.com
}

How to cite this paper: Heathcote, A. (2018). Analyticity, Truthmaking and Mathematics. Open Journal of Philosophy, 8 , 243-261.

https://doi.org/10.4236/ojpp.2018.83018

Received: April 4, 2018

Accepted: May 22, 2018

Published: May 25, 2018

Copyright (c) 2018 by author and Scientific Research Publishing Inc. This work is licensed under the Creative Commons Attribution International License (CC BY 4.0).

http://creativecommons.org/licenses/by/4.0/

\section{(c) (i) Open Access}

\begin{abstract}
Whereas for many truths, truthmaker theory offers a plausible account, there are certain kinds of truths for which the theory seems less helpful: principally (though not exclusively) analytic truths. I argue that an augmentation of the usual idea of truthmakers can solve this problem. Moreover that once solved we are able to look afresh at the nature of mathematics, whether conceived as analytic or synthetic, necessary or contingent, and reduce the ontological options. I also argue that it was Quine's reformulation of analyticity, deployed in place of the correct Leibniz-Wolff-Kant account, which led to his holistic account of knowledge and pragmatist account of scientific revisability.
\end{abstract}

\section{Keywords}

Truthmakers, Analytic Truths, Mathematics, Necessity

\section{Introduction}

The idea that truth supervenes on being is an attractive one, and goes back to Aristotle in the Categories.

Statements and beliefs, on the other hand, themselves remain completely unchangeable in every way; it is because the actual thing changes that the contrary comes to belong to them. For the statement that somebody is sitting remains the same; it is because of a change in the actual thing that it comes to be true at one time and false at another. Similarly with beliefs. Hence at least the way in which it is able to receive contraries-through a change in itself-would be distinctive of substance, even if we were to grant that beliefs and statements are able to receive contraries. However, this is not true. For it is not because they themselves receive anything that statements and beliefs are said to be able to receive contraries, but because of what has happened to something else. For it is because the actual thing ex- 
ists or does not exist that the statement is said to be true or false, not because it is able itself to receive contraries (Categories $4 \mathrm{a}$ 35-4b 11-see (Barnes, 1984))

and also later, at $14 \mathrm{~b}$ :

There are, then, many ways of speaking of the prior. There would seem, however, to be another manner of priority besides those mentioned. For of things which reciprocate as to implication of existence, that which is in some way the cause of the other's existence might reasonably be called prior by nature. And that there are some such cases is clear. For there being a man reciprocates as to implication of existence with the true statement about it: if there is a man, the statement whereby we say that there is a man is true, and reciprocally-since if the statement whereby we say that there is a man is true, there is a man. And whereas the true statement is in no way the cause of the actual thing's existence, the actual thing does seem in some way the cause of the statement's being true: it is because the actual thing exists or does not that the statement is called true or false. Thus there are five ways in which one thing might be called prior to another. (Categories 14b, 19-24)

It is a simple and powerful intuition. Expressed as a conditional: if the world were different in however so small a way, the sentences that are true would have to be different as well.

However, the converse to this principle is not so clear. Could there not be a difference in the set of true sentences without there being a corresponding alteration in being? Wouldn't analytic sentences be a clear case in point?

Enter truthmaker theory. The truthmaker theorist is primarily motivated by the credo truth supervenes on being in a strong form: all truth supervenes on being. The idea is that all true sentences must be made true by something: truths cannot simply float free. The usual thing has been to suppose that the things that make sentences true, their truthmakers, are states of affairs, and it has mostly been in these terms that the theory has been constructed-mostly, in recent years, by David Armstrong. But again: what of analyticities? These are not discussed by Armstrong; though he discusses arithmetic to some degree, and necessities at length, there is no indication of what he would make of "Bachelors are unmarried, unwidowed, adult males"? Or, "Triangles have three angles"? Being seems silent here. An exclusive focus on states of affairs seems to have led us astray. [See (Armstrong, 1997) and (Armstrong, 2004). Also see (Heathcote, 2003, 2006, 2012, 2014)]

But perhaps (it might be argued), post-Two Dogmas, the analyticities should not be regarded as a special class of truths at all. Perhaps the analytic-synthetic distinction is a graded matter, one that makes all sentences, to some degree or other, empirical, with the degree determined by pragmatic considerations. But if all are empirical then this might suggest (and this is in a teasing vein, since we 
know that Quine would have vigorously resisted this way of talking) that no sentences are purely analytic and all sentences have truthmakers, since it is through empirical evidence that Being speaks to us. So, a Two Dogmas' view of analyticities gives truthmaker theorists a way out of the problem, a way compatible with cleaving to states of affairs.

I argue in this paper that truthmaker can deal with analytic truth, and should, but that in order to do so the truthmakers need to be augmented by including relations of parthood between concepts. This is a return to Kant's notion of analyticity. I then argue that Quine's notion is inadequate as it stands but that it has an important logical relation to Kant's notion. I go on to suggest that armed with this truthmaker account of analyticity we can better understand what it means to say that arithmetic is either analytic or synthetic. In fact getting a better grip on analyticity promises to help us with many areas of metaphysics. The thought that truthmaker theory should be able to deal with analyticities is encouraged, ironically, by Quine himself, for here are the words with which he defines analyticity:

But Kant's intent, evident more from the use he makes of the notion of analyticity than from his definition of it, can be restated thus: a statement is analytic when it is true by virtue of meanings and independently of fact. (Quine, 1951: p. 21) [Reprinted with changes and corrections in Quine (1953) - see also (Quine, 1991). Quine's scepticism about the analytic/ synthetic distinction is also argued, with different emphasis, in "Truth by Convention" and "Carnap and Logical Truth", both reprinted in Quine (1966). Many surely must have noticed that Quine's arguments in his (Quine, 1951) were proceeded closely by a series of six articles that appeared in Analysis, starting in 1949, by Friedrich Waismann, an emigré at Oxford from Nazi Germany. See Waismann (1949-53), and also the articles from (Waismann, 1945) and (Waismann, 1946). In light of this it would be more correct to call the doctrine of Two Dogmas the Waismann-Quine doctrine.]

True by virtue of suggests truthmaking, even if not by states of affairs.

\section{Truthmaking}

The definition of the truthmaking relation is encapsulated in the following basic claim:

\subsection{Truthmaker Defn}

- If $s$ is a truthmaker for proposition $A$, designated $s m A$, then it is necessarily the case that if $s$ obtains then $A$ is true.

The embedded conditional in the Truthmaker Definition is intended to be a natural conditional-that is, it signals sole dependency. Note that it cannot be strengthened to an 'if and only if conditional, because $A$ may also be true due to the obtaining of some other truthmaker. We now have the main claim of truth- 
maker theory-a claim that may, as Russell said, seem so obvious that it is hard to imagine anyone denying it.

\subsection{Primary Truthmaker Axiom}

- For any true proposition $A$ there is an $s$ such that $s w A$.

In other words, no true proposition exists that is true independently of the truthmakers that obtain, nothing is true "all by itself". It is like the property of being a father: it is the existence of children that make one a father: no one can be a father "all by himself". Armstrong calls this principle truthmaker maximalism and assumes it - though he admits he has no proof of it. It would be denied by someone who thinks that a plausible case could be made that there are some truths that have no truthmakers at all, certain necessary truths, say.

Thus far nothing has been said as to what the truthmakers are. Usually it is assumed that they are states of affairs, but neither the Truthmaker Definition nor the Truthmaker Axiom require this. Here we make this assumption explicit:

\subsection{Ontological Axiom}

- The set of truthmakers is coextensive with the set of set of states of affairs.

It is this axiom that will be modified/rejected in the account that is to follow: the states of affairs, as usually understood, will need to be supplemented in their role as truthmakers. We will not need to modify either the Truthmaker Definition or the Truthmaker Axiom. For the rest of this section however I will assume the Ontological Axiom.

Then in addition to these three claims we have a number of subsidiary propositions which put flesh on the account. Here they are.

1) There are no truthmakers for untrue propositions.

2) For all $s$, there is some $A$, such that $s w \rightarrow$.

3) If $s w A$ and $t w B$ then $s \oplus t m A \& B$ where $s \oplus t$ is the mereological sum of the truthmakers $s$ and $t$, the co-obtaining of both states of affairs. This sum, $\oplus$, is commutative, idempotent, and associative. States of affairs are closed under this operation.

4) If $s w$ A then $s w A \vee B$, for any $B$. (The converse does not hold.)

5) We can define the Universe $U$ of states of affairs as that for which, given any state of affairs $s, s \oplus U$ is just $U$.

With these axioms the states of affairs with the single operation $\oplus$ is a weak algebraic structure, namely a semilattice.

[Of course many of these axioms go back in some form or other to (Mulligan et al., 1984). See also (Armstrong, 2004) and (Read, 2000)—with useful clarification on 4) in the latter paper. Note that, with (Rodriguez-Pereyra, 2009) and (2009), I reject a generalised entailment principle (if an $s$ makes a proposition true then it makes true everything entailed by that proposition). It has been claimed that truthmaker theory with the entailment principle will collapse in various ways - the above account is immune to these collapse arguments, for 
which see (Heathcote, 2003)]

If we assume bivalence then the first of these subsidiary axioms tells us simply that no false proposition has a truthmaker. One could say that a necessary and sufficient condition for a proposition to be true is that there be a truthmaker for that proposition. The second tells us something more: it tells us that there are no states of affairs that are not the truthmakers for some proposition (note: this would not be true if we replaced "proposition" by "sentence" for if sentences are finitary entities then there will be states of affairs that make no sentence true. In other words, no states of affairs are idle, they all do work as truthmakers. The third claim tells us that combining truthmakers by forming the mereological sum of them, provides a truthmaker for the conjunction of propositions. (Conceptually, it is important not to confuse the "this-and-that" of states of affairsi.e. mereological sum-with the idea of "this proposition being true and that proposition being true". In ordinary language these do get run together, but lack of clarity here only leads to confusion between the semilattice of states of affairs and the far richer structure of the algebra of propositions.)

Assuming the existence of $U$ provides a simple solution to the problem of true negative existentials, such as "there are no unicorns", "there are no $10 \mathrm{GeV}$ Higgs Bosons", "there is no Santa Claus", etc. The truthmaker for all of these is $U$, since if there are no unicorns, for example, then it is the absence of Unicorns in the entire Universe that makes that true.

There is a further axiom which we will not assume here, since it is not needed for what will follow-and it does not appear in the older truthmaker accounts, or in many mereological systems. Nevertheless it has considerable plausibility.

\subsection{Void}

We can define the null states of affairs $V$ (for "void") to be that for which, for every state of affairs $s, s \oplus V$ is just $s$.

$V$ can be understood to be the overlap of non-overlapping states of affairs. This axiom would have the advantage that it will give the algebraic structure a nicer form: it will turn it into a monoid, since $V$ will then become an additive identity element. (One can see that $V$ and $U$ are algebraically dual to one another.) We will also not introduce a notion of complementation for states of affairs; even if it might have some function in a different context it is not needed for the theory of truthmaking. This is another way in which our structure falls short of a Boolean algebra.

It should be emphasised that nothing here tells us that a proposition has only one truthmaker. There are lots of propositions that have many. For example, that some student in the class is over 5 feet tall, may have every student in the class, with his or her height, as a truthmaker. So it will not be true that corresponding to every true proposition there will be only one truthmaker-thus "correspondence" in the "correspondence theory of truth" should never have been taken to mean 1:1 correspondence.

In this account there are no disjunctive states of affairs; to think that there 
should be is a category mistake-or, what amounts to the same thing, a use/mention confusion. Disjunctions exist at the level of propositions or sentences, and are defined by their truth conditions. States of affairs have no truth conditions. In the same way no states of affairs are properly said to be "negative". To say that the state of affairs of Socrates being dead-to take an example made famous by Russell-is negative is simply to adopt an attitude toward that fact. But the state of affairs simply is the case. [See (Russell 1921) and (Russell 1948) for this problem.]

We can also define parts of states of affairs in the following way.

\subsection{Parts of States of Affairs}

- A state of affairs $s$ is a part of a state of affairs $t$ if and only if $s \oplus t$ is just $t$. Thus all states of affairs are parts of $U$ (and $V$ if we were to allow it is part of all states of affairs.)

The other thing is that we make no assumption that spatially distinct states of affairs are separate from one another. We know from quantum mechanics that that is no longer a tenable position. And even though we are not attempting to follow quantum mechanics in full here, there is no point in imposing unnecessary and, as we now know, quite false, restrictions on states of affairs.

We now have enough for the truthmakers of propositions. But analyticity is often taken to be to do with sentences and so we need to extend the truthmaker account to these, letting " $S$ " stand for sentences.

\subsection{Truthmaker Axiom for Sentences}

1) If there exists an $s$ such that $s w S$ then $S$ is true; ii) For any true sentence $S$ that expresses a proposition $A$ if $s$ is such that $s m A$ then $s \rightsquigarrow S$ when $S$ is so understood.

It should be noted that we do not strengthen the final conditional clause to an 'if and only if because this might seem to close down the possibility of analytic sentences at the outset. The idea of analytic sentences is that they are made true by relations of meaning between semantic components of those sentences.

Note also that the second clause solves a problem about ambiguity: suppose that a sentence expresses two propositions, one true and one false, then condition 2) above says that only the sentence understood in the sense in which it is true will have the truthmaker.

This is enough on truthmaker theory. My purpose has not been to argue for truthmaker theory-that has been done elsewhere. My present purpose is to employ it in, perhaps, its hardest case: analytic truth-and, by extension, arithmetical truths-and to give a surprising but, I hope, plausible solution to what has become a tangle of ad hoc doctrines, some of which are absurd or unfounded.

\section{Kant and Quine}

Kant's reason for believing analytic judgements to be a priori necessary is given 
in the following:

That "bodies are extended" is not an empirical judgment, but a proposition which stands firm a priori. For before addressing myself to experience, I already have in my conception all the requisite conditions for the judgement, and I have only to extract the predicate from the conception, according to the principle of contradiction, and thereby become conscious of the necessity of the judgment, a necessity which I could never learn from experience. (Critique of Pure Reason Introduction, iv, p. 51 (Kant, 1781))

This is easy to understand: a concept (the subject, A) can be decomposed into, or analysed into, several sub-concepts. A judgement-we will take the general form of this to be $A$ is $c(u)$-is analytic when it asserts that the predicate is one of those sub-concepts. Using ":=" as a symbol which can be read as "is decomposable into" we can write, to a first approximation, the general form as:

$$
C(A):=\left\{c\left(u_{1}\right), c\left(u_{2}\right), \cdots, c\left(u_{n}\right)\right\}
$$

and then

$$
c\left(u_{i}\right) \in\left\{c\left(u_{1}\right), c\left(u_{2}\right), \cdots, c\left(u_{n}\right)\right\} .
$$

We can easily see from this the basis of the claimed a priori of the judgement and also the necessity (the second sentence is a necessary truth-in any world in which $\left\{c\left(u_{1}\right), c\left(u_{2}\right), \cdots, c\left(u_{n}\right)\right\}$ exists $c\left(u_{i}\right)$ is a member). We can also see what it means for Kant to say that its denial would lead to a contradiction. Thus A is not $c\left(u_{i}\right)$ directly implies:

$$
c\left(u_{i}\right) \in\left\{c\left(u_{1}\right), c\left(u_{2}\right), \cdots, c\left(u_{n}\right)\right\} \& c\left(u_{i}\right) \notin\left\{c\left(u_{1}\right), c\left(u_{2}\right), \cdots c\left(u_{n}\right)\right\} .
$$

A synthetic judgement is when the predicate is not a member of the decomposition set-and note that this is an all or nothing affair: a judgement is synthetic if and only if it is not analytic. And finally an analytic sentence is simply one that expresses an analytic judgement.

Seeing how naturally necessity and a priority arise is crucial for understanding the failure of Quine's analysis in Two Dogmas. Here is Quine's interpretation:

Kant conceived of an analytic statement as one that attributes to its subject no more than is already conceptually contained in the subject. This formulation has two shortcomings: it limits itself to statements of subject-predicate form, and it appeals to a notion of containment which is left at a metaphorical level. But Kant's intent, evident more from the use he makes of the notion of analyticity than from his definition of it, can be restated thus: a statement is analytic when it is true by virtue of meanings and independently of fact. (Quine, 1951: p. 21. See also (White, 1950) and (White, 1956).

It is odd on the face of it that Quine rejects Kant's actual account of analyticity and focusses instead on a conjectural characterization that is notable only for its 
vagueness. How is an analytic statement true by virtue of meanings? Aren't the truth values of all sentences dependent to some extent on the meanings that those sentences have-at least to the extent that the following counterfactual holds: if the sentence qua linguistic string had a different meaning than the meaning it actually has then its truth value might have been different? But perhaps due to the vagueness of Quine's account it looks, superficially, as though it encompasses Kant's more precise account. This, I think, is wrong-in virtue of this redefinition the necessity and a priori character vanish. (Quine's claims about the shortcomings of Kant's view are also strange. The conceptual containment can be rendered as set-theoretic containment, as above, a notion that Quine accepts; and the subject-predicate form is nowhere gone beyond in Quine's own account.)

There is another fundamental difference that Quine does not note: Kant's distinction is a division of the class of true judgements, not of sentences true or false. Some sentences, for example those that are false or self-contradictory, or those that are conditional, will be neither analytic nor synthetic. Quine is unclear but he appears to think of the distinction as exhaustive on the set of sentencesas Brentano intended his own redefinition to be-and speaks throughout of "analytic sentences" and not of "analytic truths". And because many have followed Quine's redefinition here, this mistake of scope now runs throughout the post-Two Dogmas discussion of analyticity.

In short, Quine's conclusions about the failure of the analytic/synthetic distinction are due to his mistaken account of what analyticity consists in-and importantly, it was this alteration that directly facilitated the holistic doctrine at the end of Two Dogmas.

To see this consider the following as an encapsulation of Quine's working definition given above:

\subsection{Q-Analytic Sentences}

- If a true sentence $S$ has a truthmaker $m$ that is the relation expressed by a meaning equivalence (or meaning inclusion) and it has no other state of affairs $s$ as a truthmaker then $S$ is Quine-analytic.

The last clause gives us the idea that the sentence is true solely in virtue of meanings and "independently of fact".

We also need for this an explication of meaning equivalence/inclusion.

\subsection{Meaning Inclusion}

- If a true sentence has the general form " $\alpha$ is equivalent in meaning to, or contains, $\beta$, where $\alpha$ or $\beta$ are to be replaced by names of general terms, then the sentence is a meaning inclusion. It is a meaning equivalence when "or contains" can be omitted.

The state of affairs so expressed by a meaning equivalence is a general instance of an equivalence relation, defined on general terms, and satisfies the usual 
properties.

To see where things go wrong in the Quinean account, let us consider the following example of an analytic sentence:

(3) Triangles are three-sided polygons.

The Quinean conception of analyticity is that this sentence is "true in virtue of meanings". Thus although it appears to be about triangles and not words, as indicated by the absence of quotation marks around the word "triangles", the claim that it is analytic suggests that this is a surface semantic defect: the truthmaker for this claim is not a fact about triangles but a fact about the general term "triangle". Analytic sentences, as used by Quine, are systematically deceptive in this way.

But in line with the Quinean definition we can suggest that the truthmaker for (3) is the following meaning equivalence:

(4) "Triangle" is equivalent in meaning to "three-sided polygon".

There are two ways that this meaning equivalence could have come about: by stipulation, as when someone says: "henceforth I will call all three-sided polygons by the name 'triangle'." Or the above could be a report of usage, so that it tells us how the words are actually used. But however it has come about (4) expresses a relationship of meaning equivalence: a state of affairs in which linguistic items are so related. The semantic relationship, expressed by (4), is, on Quine's doctrine of analytic sentences, a plausible candidate for the truthmaker of (3). (To be clear, however, note that the truthmaker for (3) is not to be the sentence (4) but the semantic equivalence relationship that (4) expresses.)

But the point is that this sentence does not depend for its truth on the existence of triangles, or even polygons.

We can bring this out by a second example.

(5) Basilisks have a fatal look.

We might be inclined to judge the sentence false for the non-existence of such creatures-and the absence of quotation marks around "Basilisks" is what might press us in this direction. However if the sentence is analytic then it can be true despite the non-existence of Basilisks. Its truthmaker is given by:

(6) "Basilisk" is equivalent in meaning to "serpent which has a toxicity so great that it can kill with a look".

Note that it is not part of the meaning of the word "Basilisk" that it be a mythological creature. This is a judgement we make about Basilisks, not something that is included in the meaning of the word. If it were included in the meaning of the word it would have the absurd consequence that it would be logically impossible for us ever to discover that Basilisks once existed, no matter how great the evidence we might uncover.

What we now have are sentences that are plausibly analytic truths according to the Quinean definition. But even if (4) and (6) are true, they aren't plausibly necessarily true: we give meaning to words, and how we do so is a contingent matter. That one linguistic term is related to another linguistic term cannot be, 
at base, anything other than a decision about how we are to use words. Thus it looks as though (3) and (5) are not necessary truths either. The point is generalizable: on Quine's account of analyticity no analytic sentences are necessary truths, and this is due simply to his adoption of a linguistic definition of "analyticity".

Of course, one might say, that this is exactly what Quine wanted to show; that the necessity of analytic sentences is a kind of fool's gold. But it is remarkable how trivially this follows from Quine's definition: no reliance on problematic attributions of circularity, no leaning on Pragmatist ideas about verification. If we were to go a step further with Quine in his contention that meaning, and therefore meaning equivalence, is a problematic notion, that it is variable, or theory-sensitive, then this will then feed directly into the account of Q-Analytic sentences, making the analytic/synthetic distinction variable, or theory-sensitive. This gives us the second part of Quine's doctrine. But note that rejection of this second part, a rejection which is now quite common, does not negate the first part: the rejection of the necessity of analytic sentences.

What makes the difference between the Kantian conception of analyticitywhere the necessity of the analytic truths follows rather quickly-and the Quinean account where it vanishes-equally quickly? The answer, I suggest, is simply the shift from concepts to linguistic items like general terms. Concepts have fixed relations to the sub-concepts that make them up. The concept of triangularity has a fixed relation to polygon, closed figure that has three straight sides, figure that has three internal angles. This fixed relation can be expressed in many natural languages: it does not matter whether the surface language is Classical Greek, Latin, German, or Cherokee. How the concept relates to its parts is fixed and immutable - and it is from this immutability that the necessity arises.

By contrast the Quinean account eschews concepts in order to pitch the definition of analyticity at the level of relations of meaning equivalence between general terms. These relations can hardly be anything other than contingent. It is a contingent matter that the word "triangle" has the relation of being equivalent in meaning to "three-sided polygon", and that sameness of meaning could change tomorrow, by an act of fiat. This is reflected in Quine's own words at the close of section IV of Two Dogmas.

It is obvious that truth in general depends on both language and extra-linguistic fact. The statement "Brutus killed Caesar" would be false if the world had been different in certain ways, but it would also be false if the word "killed" happened rather to have the sense of "begat". Hence the temptation to suppose in general that the truth of a statement is somehow analyzable into a linguistic component and a factual component. Given this supposition, it next seems reasonable that in some statements the factual component should be null; and these are the analytic statements. But, for all its a priori reasonableness, a boundary between analytic and synthetic statements simply has not been drawn. That there is such a distinction to be drawn at all is an unempirical dogma of empiricists, a metaphysical article 
of faith. (Quine, 1951: p. 34)

But contingency at this level has no deep philosophical consequences because it has no deep philosophical origin-it simply reflects our ability to re-stipulate our usage of words. Quine's conclusions follow from his initial decision to redefine analyticity into a statement about the relations of meaning equivalence between words, and then to notice that meaning can change across time.

In particular it cannot underwrite the generalisation of Euclidean geometry to Non-Euclidean geometry, or say anything about the "law of excluded middle" and whether that law is necessary or not. Thus when Quine said:

Conversely, by the same token, no statement is immune to revision. Revision even of the logical law of the excluded middle has been proposed as a means of simplifying quantum mechanics; and what difference is there in principle between such a shift and the shift whereby Kepler superseded Ptolemy, or Einstein Newton, or Darwin Aristotle? (Quine, 1951: p. 40)

This entire conclusion is a non sequitur. Statements can indeed be revised, but that has nothing to do with the change from a Ptolemaic model of the solar system to a Keplerian model, and likewise nothing to do with the shift from a Newtonian theory of gravitational laws to an Einsteinian theory. Quine is shifting from the revisability of sentences to the revisability of (but, more properly, change in our understanding of) the conceptual content of those statements, and thence to the revisabilty of our theories about the world: in short, he is committing a kind of use/mention fallacy: sliding between words as mere syntactic strings, and words as characterised by the concepts they express and the referents they designate, and thence to the theories that embody them.

This semantic sliding (for want of a better name) runs through all of Two Dogmas but it culminates in the revisability doctrines of the final section. Once noticed it is so flagrant as to be breathtaking. One does not make the change from classical logic to a quantum logic by making changes to the meanings of general terms. Rather, one mathematical structure is replaced by another, with an associated change in concepts; and the words used to designate things in the theory are allowed to carry over if the essential properties are preserved. (Quine is only ever concerned with Reichenbach's suggestion of a three-valued logic for QM, not the more well-known von Neumann-Birkhoff-Mackie suggestion of replacing the Boolean structure with an orthomodular lattice.) Reusing linguistic items to express the new theory is an entirely superficial decision, of less importance than whether one is considering writing the theory in French or English. Thus we cannot, and do not, "accommodate recalcitrant experience" by simply changing what words mean and then, by some means, "redistributing truth values"-as though, in general, we had any choice in the matter of what statements are true once meanings are fixed. We change our theories, and a change in the meanings of words may follow this other deeper change.

The debate between Boghossian and Harman (Boghossian \& Peacocke, 2000) in the 1990's on analyticity had essentially agreed with Quine's view (in Two 
Dogmas) that a notion of true in virtue of meaning is unable to ground an idea of necessary truth (see Boghossian (1996) and Harman (1996)). Indeed, it is asserted that this is the "predominant view" (an assertion I don't contest, though I do lament it). But this consensus has been attained far too cheaply-by not seeing that it was Quine's initial redefinition of analyticity and his eschewing the relations between concepts, in the manner of Leibniz and Kant, that gives us the notions of necessity and a priority, rather easily. Thus what the consensus has really bought is a conditional: if we accept Quine's redefinition of analyticity then there will be no grounding of necessity on analytic sentences. I believe this conditional to be true, while the antecedent asks us to do something we shouldn't do: we shouldn't accept his redefinition, for it was based on the very meaning scepticism that Two Dogmas concluded with-thus the argument was always a petitio. (C.f. (Katz, 1974, 1997) and (1997); also (Mates, 1951) and (Martin, 1959) (Martin, 1952) for cogent early criticism.) The current view is allied with Sullivan (2008).

\section{Augmented Truthmakers}

Nevertheless we now have two notions of analyticity, the Kantian and the Quinean, which have two different implications for the necessity of analytic statements. Now we return to the question of how to accommodate both of them into an account of truthmakers.

The first thing to note is that the Quinean account seems to require no substantial modification to the truthmaker account that was described in section one, above. Words have properties and can make sentences about them true. If we eschew the sceptical Quinean doctrine about meaning and meaning equivalence then the statement about analyticity that Quine begins with need give us no trouble: a statement is analytic when it is true by virtue of meanings and independently of fact. Our definition of Q-analytic sentences will suffice, though we must swallow the consequence that none of these will be necessities, for no deep reason.

But Kant's account of analyticity is a different matter; it deals in concepts, not words, and thus takes us into the very deep and ancient controversies as to what these concepts are. But the truthmaker account described above already countenances propositions: we can build on this to allow for concepts, and come back later to the deeper ontological questions.

If we follow Kant's lead, in a judgement there is a subject-concept and a predicate-concept. The judgment will be analytic if the subject-concept contains the predicate-concept as a (not necessarily proper) part. The judgment will be synthetic if it is not analytic. The containment here is best represented through the mereological part-whole relation, rather than as set-theoretical containment, since the latter puts the relation at the wrong level. Mereological sum seems to work perfectly well for concepts: concepts can be aggregated: truth and justice; redness and tallness; triangularity and right-angled. Of course not all such ag- 
gregations will be useful to us-perhaps very few-but they make sense as concepts. The most obvious example of a useful conceptual sum is knowledge as justified, true belief. So we can break the concept of the subject A of the judgement into a sum of components:

$$
C(A):=\left[c\left(u_{1}\right) \oplus c\left(u_{2}\right), \oplus \cdots, \oplus c\left(u_{n}\right)\right]
$$

Then a judgment of the form

$A$ is $u_{i}$ will be analytic when $c\left(u_{i}\right)$ is a part of $\left[c\left(u_{1}\right) \oplus c\left(u_{2}\right), \oplus \cdots, \oplus c\left(u_{n}\right)\right]-$ i.e. when

$$
c\left(u_{i}\right) \oplus\left[c\left(u_{1}\right) \oplus c\left(u_{2}\right), \oplus \cdots, \oplus c\left(u_{n}\right)\right]=\left[c\left(u_{1}\right) \oplus c\left(u_{2}\right), \oplus \cdots, \oplus c\left(u_{n}\right)\right] .
$$

So, in the obvious way, all red objects are coloured is analytic because the concept of colour is already a component of the concept of redness. We can sum this up in a definition:

\section{Kantian Analyticity}

- The judgment ' $A$ is $u_{i}^{\prime}$ is analytic for $C(A):=\left[c\left(u_{1}\right) \oplus c\left(u_{2}\right), \oplus \cdots, \oplus c\left(u_{n}\right)\right]$ if and only if

$$
c\left(u_{i}\right) \oplus\left[c\left(u_{1}\right) \oplus c\left(u_{2}\right), \oplus \cdots, \oplus c\left(u_{n}\right)\right]=\left[c\left(u_{1}\right) \oplus c\left(u_{2}\right), \oplus \cdots, \oplus c\left(u_{n}\right)\right] .
$$

In the same way as before we can see that Kantian analytic judgments are necessary, since their denials are self-contradictory. Likewise we can agree with Kant that such judgements can be known a priori. We can also see that if a judgment is Kantian analytic the sentence that expresses it will be Quinean analytic. This is because the general terms that express the concepts must be related by meaning inclusion, as per the definition in section two above. However because general terms only express their concepts contingently, the necessity of a Kantian analytic judgement does not mean that the Quinean analytic sentence is necessary. The appearance of necessity is gained only by shifting illicitly from the sentence to the judgement that the sentence expresses, or in other words by holding the meaning, and thus the relation between concepts, fixed.

In a synthetic judgement the predicate-concept is not contained in the subject-concept but goes beyond it to assert something new about the subject. Thus whether such a sentence is true or false can only be determined by ascertaining whether the additional property holds. We cannot leap to the conclusion that synthetic judgements are contingent-there is nothing that tells us this. Likewise there is nothing that tells us that such judgments are only knowable a posteriori. Seeing this might be said to be Kant's great insight. In fact we can draw no conclusions at all about the nature of synthetic judgements from the analysis of analytic judgements. This has ramifications for the assessment of mathematics: for it does not follow that mathematics is necessary, contingent, or a priori, merely from the fact that it is non-analytic, if it is so. (Of course we can conclude that if there are any contingent truths that they can't be analytic.)

What has enlarging the class of truthmakers to include relations between 
concepts brought us? The positive gains are obvious, but we might wonder if there are any costs that accompany them.

As already noted the initial statement of the idea that truth supervenes on being goes back to Aristotle, in the Categories. The point there is the priority of being over truth. But Aristotle simply gives one illustrative example, and he does not generalise the point to all truths. This left the question unanswered: do all true sentences supervene on being? In his (2004) Armstrong had noted that simply saying that every truth has a truthmaker does not in itself tell us what those truthmakers are, or if they are all of the same kind.

We have noticed already that simply to accept the idea that truths have truthmakers by no means dictates just what these truthmakers are. The question what truthmakers are needed for particular truths (what we take to be truths!) can be, and regularly is, as difficult as the question of metaphysics, the question of ontology. (Armstrong, 2004: p. 4)

What I have suggested here is that the states of affairs be augmented with relations of parthood between concepts, and that these are the truthmakers for analytic truths-and these also be considered states of affairs of a kind. In the first instance these concepts should perhaps be understood as mental entities. But concepts needn't be merely mental entities. Some concepts answer to genuine properties in the world. Triangularity exists, and triangles are three-sided polygons. The necessity of the analytic statement is then reflected in the world, as a relationship between properties. In this case the property of triangularity is simply a specific kind of polygon, one with three sides. Likewise a red object is just a specific kind of coloured object. This suggests that properties also obey a part-whole logic and that this is responsible for the necessity of these relations de re.

But a judgement can still be analytic even when there are no properties that answer to the concepts: just provided that the concepts have the proper relation of parthood the judgement will be analytic and necessary. Thus the judgment basilisks have a fatal glance is analytic and necessary despite there being no basilisks and nothing having a fatal glance. The same might be said of the judgement God is omniscient. However when the concepts do not answer to genuine properties the usual way of stating the judgment leads to a form of use/mention confusion. For saying 'Basilisks have a fatal glance' implies, with the absence of quotation marks, that we are speaking of basilisks. It would be less misleading in this context to say 'the concept basilisk is part of the concept creatures with a fatal glance'-in which there is no implication that we are speaking of things that don't exist. Thus the Parmenidean paradox is inextricably bound up with the issue of analyticity, and, we might hope, can be resolved along with it.

One of the clear conclusions that we can draw from this discussion is that analytic sentences have, in themselves, no ontological consequences. They may be true and necessarily true regardless of whether there are properties answering 
to the concepts: what makes them true is simply the relation between the concepts themselves. Analytic truth does not imply ontology.

There is a converse to this: that if a judgement is true and synthetic that there must be something that answers to the concepts. I don't have a knock-down argument for this but I think I can offer something sufficient to render it plausible. First consider an example: rattlesnakes are found in the South-West. This is true and synthetic. It is synthetic because the predicate-concept creatures found in the South-West is not a part of the concept of rattlesnakes, rather the property is true of rattlesnakes. We can readily understand the concept rattlesnake without being at all committed to understanding that as including creatures that are found in the South-West, and our understanding would not be diminished if the South-West eradicated every last rattlesnake. So it seems to be synthetic, contingent and knowable only a posteriori. But if we consider an analogous judgement with a concept that does not correspond to anything in the world then we would not judge it true. Thus "Basilisks are on Wall St.", whatever its metaphorical resonance, is synthetic and false for want of any basilisks. Any synthetic judgement with an empty subject concept will be false, for we are predicating something of a thing that does not exist, where the predicate is not a part of the subject, where the predicate makes a substantive claim about the subject that goes beyond what is in the subject. There is thus nothing to ground the truth in this case, no truthmaker. And so it must be false. We can summarise this by saying: synthetic truth does imply ontology.

Many philosophers have thought that the question: is arithmetic analytic or synthetic? clear as it stands, and needing a straightforward answer. I see no such need. Surely some statements of arithmetic may be analytic and others not (in particular they may be conditionals) as in other sciences. (C.f. Stenius, 1965). It has often been pointed out that, taking Kant's definition of analyticity strictly, and despite what he claimed, $5+7=12$ is neither analytic nor synthetic, since it is not a judgement. See (Kneale \& Kneale, 1962: p. 357).

\section{History of a Concept}

Plato held that, for (3), the Idea, or Form, of triangularity was related to the general Form of polygon. through some kind of part-whole relation (just how this was to be stated and how it would work was, and is, of course, a vexed issuesee (Harte, 2002) for a discussion of parts and wholes in Plato's metaphysics). However in virtue of these Ideas, or Forms, being objective and timeless, and theorems about these Ideas being knowable a priori seemed plausible to think, in the post-Euclid tradition, that the relations held necessarily. Thus a non-trivial statement about triangles such as Pythagoras' theorem: in a right triangle the sum of the squares of the sides equals the square of the hypotenuse, which is known a priori demonstration, and is necessary, through the relation of the Ideas, or Forms.

But by the time we come to Hume the concept of Ideas and their relations has 
become entirely subjective, they are now mental entities, ideas in the modern sense of that term, not separately existing Universals. And yet Hume keeps the doctrine that their relations are knowable a priori and that they are necessary.

Of the first kind [Relations of Ideas] are the sciences of Geometry, Algebra, and Arithmetic; and in short, every affirmation which is either intuitively or demonstratively certain. That the square of the hypotenuse is equal to the square of the two sides, is a proposition which expresses a relation between these figures. That three times five is equal to the half of thirty, expresses a relation between these numbers. Propositions of this kind are discoverable by the mere operation of thought, without dependence on what is anywhere existent in the universe. Though there never were a circle or a triangle in nature, the truths would forever retain their certainty and evidence. (Hume, 1772: p. 25)

This passage taken alone could be read as an able expression of the foregoing Platonic notion of Ideas; it is only when one conjoins it with earlier passages (for example, the introduction to section II-see Hume, 1772: p. 17). That one understands that these Ideas are mental entities. But our argument above makes full sense of Hume: mathematics can be underwritten by the relations of ideas and thus be a priori necessary. But this is ontologically noncommittal, so Hume is not obliged to weigh in on questions of the reality of mathematical entitiesand he (mostly) does not.

Leibniz continued another aspect of the Medieval tradition by making a linguistic turn and spoke of relations of inclusion of predicate in subject, calling these relations "analytic". His doctrine has now been largely forgotten outside the circle of Leibniz scholars but is worth recalling, since it explains why necessary truths were called "analytic" in the first place.

Therefore, recognising the contingency of things, I further considered what a clear notion of truth might be, for I hoped, and not absurdly, for some light from the direction on how necessary and contingent truths could be distinguished. Now, I saw that it is common to every true affirmative proposition, universal and particular, necessary or contingent, that the predicate is in the subject, that is that the notion of the predicate is involved somehow in the notion of the subject. And this is the source [principium] of infallibility in every sort of truth for that being who knows everything a priori.

...But in contingent truths, even though the predicate is in the subject, this can never be demonstrated, nor can a proposition ever be reduced [revocari] to an equality or to an identity, but the resolution proceeds to infinity, God alone seeing, not the end of the resolution, of course, which does not exist, but the connection of the terms or the containment of the predicate in the subject, since he sees whatever is in the series.

...Just as in every proportion a smaller number is in a larger one or an 
equal is in an equal, so in every truth a predicate is in the subject....But in proportions, while the analysis comes to an end, and arrives at a common measure, namely one that measures out each term of the proportion through exact repetitions of itself, in other cases the analysis can be continued to infinity, as happens in the comparison between a rational and an irrational number, such as the comparison of the side and the diagonal of a square. (Leibniz 'On Freedom’ from 1689(?), 1989: pp. 95-96)

So truths that appear necessary to us are those whose predicate can be seen to be in the subject after a finite number of steps, and thus reduced to an identity statement; truths that appear to us contingent are those for which no finite analysis will work. Necessary truths are analogous to rational numbers; contingent truths to irrationals. In this way Leibniz connects necessity and contingency to the real line-and hence to analysis in the mathematical sense. By Leibniz's conception, there were, in some sense, only analytic truths. For God, everything is analytic and necessary.

But this means that, in the language of possible worlds that many associate with Leibniz, there is only one possible world, the actual world. Leibniz's possible worlds are merely figurative ways of expressing our epistemic limitationsGod, who has no such limitation, sees just one world.

Kant dropped the analogy between contingency and incommensurable magnitudes and introduced the word 'synthetic' for all those judgements that were not analytic (though it should be noted that Kant was anticipated in this by Christian Wolff and others, early in the 18th Century-see (Proust, 1989) for more on this). This was a considerable improvement, since Leibniz had no clear way of saying what it is that God is seeing when he sees "the containment of the predicate in the subject". The mathematical analogy remained unworked out by him and probably could not be so.

But though Kant's simplification is a marked improvement it does not make it obvious how we are to make the decision that a judgment is synthetic. How do we decide, for example, which statements of arithmetic are synthetic or analytic? I see no easy answer to this. In fact it may be easier simply to do an end-run around this and go straight to the issue of whether it is necessary or contingent. But truthmakers can be expected to help here as well-for the best way of making progress on metaphysical questions is to cleanly separate ontological questions from those that are semantic or epistemological. This, one might say, was Aristotle's great initial insight - an insight that was lost in the $20^{\text {th }}$ Century.

\section{References}

Armstrong D. M. (1997). A World of States of Affairs. Cambridge: Cambridge University Press. https://doi.org/10.1017/CBO9780511583308

Armstrong, D. M. (2004). Truth and Truthmakers. Cambridge: Cambridge University Press. https://doi.org/10.1017/CBO9780511487552

Barnes, J. (Ed.) (1984). The Complete Works of Aristotle Vol. I. Bollingen Series, Prince- 
ton, N.J.: Princeton University Press.

Boghossian, P. A. (1996). Analyticity Reconsidered. Noûs, 30, 360-391. https://doi.org/10.2307/2216275

Boghossian, P., \& Peacocke, C., Eds. (2000). New Essays on the A Priori. Oxford: Oxford University Press. https://doi.org/10.1093/0199241279.001.0001

Harman, G. (1996). Analyticity Regained? Noûs, 30, 392-400. https://doi.org/10.2307/2216276

Harte, V. (2002). Plato on Parts and Wholes. The Metaphysics of Structure, New York: Oxford University Press. https://doi.org/10.1093/0198236751.001.0001

Heathcote, A. (2003). Truthmakers and the Alleged Need for Relevance, Logique et Analyse, 46, nos 183-184, September-December 2003, pp. 345-364.

Heathcote, A. (2006). Truthmaking and the Gettier Problem. In S. Hetherington (Ed.), Aspects of Knowing. Epistemological Essays (Ch. 10, pp. 151-167). Amsterdam: Elsevier.

Heathcote, A. (2012). Gettier and the Stopped Clock Analysis, 72, 2, April, 2012, pp. 309-314.

Heathcote, A. (2014). Truthmaking, Evidence Of, and Impossibility Proofs. Acta Analytica, 29, 363-375.

Hume (1772). David Hume: An Enquiry Concerning Human Understanding. In T. L. Beauchamp (Ed.), The Clarendon Edition of the Works of David Hume. Oxford.

Kant, I. (1781). Critique of Pure Reason (trans. Norman Kemp Smith, 1929). London: Macmillan.

Katz, J. J. (1974) Where Things Now Stand with the Analytic-Synthetic Distinction. Synthese, 28, 283-319.

Katz, J. J. (1997). Analyticity, Necessity, and the Epistemology of Semantics. Philosophy and Phenomenological Research, 57, 1-28.

Kneale, W., \& Kneale, M. (1962). The Development of Logic. Oxford: Clarendon Press.

Leibniz, G. W. (1989). Philosophical Essays. Indianapolis and Cambridge: Hackett.

Martin, R. M. (1952). On “Analytic”. Philosophical Studies, 3, 42-47. https://doi.org/10.1007/BF02333167

Martin, R. M. (1959). The Notion of Analytic Truth. Philadelphia: University of Pennsylvania Press. https://doi.org/10.9783/9781512817829

Mates, B. (1951). Analytic Sentences. The Philosophical Review, 60, 525-534. https://doi.org/10.2307/2181423

Mulligan, K., Simons, P., \& Smith, B. (1984). Truth-Makers. Philosophy and Phenomenological Research, 44, 287-321. https://doi.org/10.2307/2107686

Proust, J. (1989). Questions of Form: Logic and the Analytic Proposition from Kant to Carnap (Translated by Anastasios Albert Brenner). Minneapolis: University of Minnesota Press.

Quine, W. V. O. (1951). Two Dogmas of Empiricism. Philosophical Review, 60, 20-43.

Quine, W. V. O. (1953). From a Logical Point of View. Cambridge, MA: Harvard University Press.

Quine, W. V. O. (1966). The Ways of Paradox and Other Essays. New York, NY: Random House.

Quine, W. V. O. (1991). Two Dogmas in Retrospect. Canadian Journal of Philosophy, 21, 265-274. https://doi.org/10.1080/00455091.1991.10717246 
Read, S. (2000). Truth-Makers and the Disjunction Thesis. Mind, 109, 67-79.

Rodriguez-Pereyra, G. (2009). The Disjunction and Conjunction Theses. Mind, 118, 427-443.

Stenius, E. (1965). Are True Numerical Statements Analytic or Synthetic? The Philosophical Review, 74, 357-372. https://doi.org/10.2307/2183359

Sullivan, A. (2008). Truth in Virtue of Meaning. Canadian Journal of Philosophy, 38, 373-397. https://doi.org/10.1353/cjp.0.0023

Waismann, F. (1945). Are There Alternative Logics? Proceedings of the Aristotelian Society, 46, 77-104.

Waismann, F. (1946). The Many-Level Structure of Language. Synthese, 5, 221-229.

Waismann, F. (1949-53). Analytic-Synthetic I, II, III, IV, V, VI. Analysis, 10, 25-40.

White, M. G. (1950). The Analytic and the Synthetic: An Untenable Dualism. New York, NY: Dial Press.

White, M. G. (1956). Toward Reunion in Philosophy. Cambridge, MA: Harvard University Press. 